\title{
A MODEL SYSTEM TO STUDY ANTIMICROBIAL STRATEGIES IN ENDODONTIC BIOFILMS
}

\author{
Carlos ESTRELA ${ }^{1}$, Gilson Blitzkow SYDNEY ${ }^{2}$, José Antonio Poli FIGUEIREDO ${ }^{3}$, Cyntia Rodrigues de Araújo ESTRELA ${ }^{4}$
}

1-DDS, MSc, PhD, Chairman and Professor of Endodontics, Department of Oral Science, Federal University of Goiás, Goiânia, GO, Brazil. 2- DDS, MSc, PhD, Chairman and Professor of Endodontics, Department of Endodontics, Federal University of Paraná, Curitiba, PR, Brazil.

3- DDS, MSc, PhD, Reader in Endodontology, Dean of the Post-graduate Program in Dentistry, Pontifical Catholic University of Rio Grande do Sul - PUCRS, Porto Alegre, RS, Brazil.

4- DDS, MSc, PhD, Biological Science Institute, Federal University of Goiás, Goiânia, GO, Brazil.

Corresponding address: Prof. Carlos Estrela - Centro de Ensino e Pesquisa Odontológica do Brasil - Rua C-245 - Quadra 546, Lote 9 - Jardim América - Goiânia, GO - 74.290-200, Brasil - e-mail: estrela3@terra.com.br

Received: January 14, 2008 - Modification: June 05, 2008 - Accepted: June 18, 2008

\begin{abstract}
$\Gamma_{\text {he }}$

he purpose of this work was to develop a model system to study antimicrobial strategies in endodontic biofilms. Enterococcus faecalis suspension was colonized in 10 human root canals. Five milliliters of Brain Heart Infusion (BHI) were mixed with 5 mL of the bacterial inoculums (E. faecalis) and inoculated with sufficient volume to fill the root canal during 60 days. This procedure was repeated every $72 \mathrm{~h}$, always using 24-h pure culture prepared and adjusted to No. 1 MacFarland turbidity standard. Biofilm formation was analyzed by scanning electron microscopy (SEM). E. faecalis consistently adhered to collagen structure, colonized dentin surface, progressed towards the dentinal tubules and formed a biofilm. The proposed biofilm model seems to be viable for studies on antimicrobial strategies, and allows for a satisfactory colonization time of selected bacterial species with virulence and adherence properties.
\end{abstract}

Key words: Biofilm. Endodontic biofilm. Enterococcus faecalis. Intracanal medicaments. Antimicrobial strategies.

\section{INTRODUCTION}

Root canal is an extraordinary microenvironment for several microbial species to attach on dentin surface and form dense bacterial biofilms ${ }^{20}$, which are prevalent on most wet surfaces and can cause environmental problems, representing a common cause of persistent infections ${ }^{2,30}$.

The stages of structural organization of biofilm, the composition and activities of the colonizing microorganisms in various environments may be different, although the establishment of a micro-community on a surface seems to follow essentially the same series of developmental stages, including deposition of a conditioning film, adhesion and colonization of planktonic microorganisms in a polymeric matrix, co-adhesion of other organisms, and detachment of biofilm microorganisms into surroundings ${ }^{30}$. The success of infected root canal treatment is dependent on inactivation of microorganisms present in biofilm and planktonic ambiance. Root canal preparation with antimicrobial agents, like chemical irrigants and/or intracanal dressings, can contribute for endodontic microbiota reduction ${ }^{5}$.

Sundqvist and Fidgor ${ }^{29}$ (2003) reported that "root canal infection is not a random event". Species that establish a persistent endodontic infection are selected by the phenotypic traits that they share and that are suited to the modified environment. Some of these shared characteristics include the capacity to penetrate and invade dentin, a growth pattern of chains or cohesive filaments, resistance to antimicrobials used in endodontic treatment, as well as an ability to grow in mono-infections, to survive periods of starvation and to evade the host response ${ }^{29}$.

E. faecalis has proved a potentially important microorganism to the colonization or overgrowth in endodontic infections, being the dominant microorganism in post-treatment apical periodontitis, and has often been isolated from the root canal in pure culture. However, it is usually also found together with other bacteria and yeasts. In mixed infections, E. faecalis is typically the dominant isolate. The pathogenicity of $E$. faecalis in endodontic infections is well documented $^{28,29}$. Several studies have been developed with different bacterial biofilm models to test the antimicrobial efficacy of endodontic medicaments ${ }^{4-6,9,27}$. Investigations have shown either antimicrobial efficacy ${ }^{27}$, or inefficacy ${ }^{5,9,20}$ of intracanal medicaments against bacterial biofilm. The planktonic or biofilm ambiance can be of influence on antimicrobial efficacy ${ }^{5,20}$.

Bacteria growing on a surface display a novel phenotype $^{15}$. A consequence is an increased resistance to 
antimicrobial agents that can result from restricted inhibitor penetration, slower bacterial growth rates, transfer of resistance genes, suboptimal environmental conditions for inhibitor activity, and the expression of a resistant phenotype ${ }^{18}$.

The large number of published studies on bacterial biofilm can certainly bring in its context contradictory positions on antimicrobial strategies, mainly due to the variability between the methodologies. Therefore, the purpose of this work was to develop a model system to study antimicrobial strategies in endodontic biofilms.

\section{MATERIAL AND METHODS}

\section{Biofilm Model \\ Tooth Preparation}

Fourteen extracted human mandibular premolars with intact cementum obtained from the tooth bank of the Brazilian Dental Research and Learning Center (CEPOBRAS, Goiânia, GO, Brazil) were selected for this study. The teeth were removed from storage in $0.2 \%$ thymol solution and were immersed in $5 \%$ sodium hypochlorite $(\mathrm{NaOCl}$, Fitofarma, Goiânia, GO, Brazil) for $30 \mathrm{~min}$ to remove organic tissues. Following periapical radiographs, standard access cavities were prepared and the coronal root canal third was enlarged using sizes 2 and 3 Gates Glidden drills (Dentsply Maillefer, Ballaigues, Switzerland). The teeth were prepared up to a size $50 \mathrm{~K}$-file (Dentsply Maillefer) $1 \mathrm{~mm}$ short of the apical foramen, using a crown-down preparation technique. During instrumentation, the root canals were irrigated with $3 \mathrm{~mL}$ of $1 \% \mathrm{NaOCl}$ at each change of file. Thereafter, the crowns were removed and tooth length was standardized to $17 \mathrm{~mm}$ (from root apex to coronal border). Root canals were dried and filled with 17\% EDTA ( $\mathrm{pH}$ 7.2) for $3 \mathrm{~min}$ for smear layer removal. This management was repeated twice. Next, the teeth were autoclaved at $120^{\circ} \mathrm{C}$ for $30 \mathrm{~min}$.

\section{Biofilm Development}

A reference strain of Gram-positive facultative anaerobic cocci (E. faecalis; ATCC 29212) obtained from the American Type Culture Collection was used for biofilm formation. The bacterial strain was inoculated in $7 \mathrm{~mL}$ of Brain Heart Infusion broth (BHI; Difco Laboratories, Detroit, MI, USA) and incubated at $37^{\circ} \mathrm{C}$ for $24 \mathrm{~h}$. The experimental suspensions were prepared by cultivating the biological marker on the surface of Brain Heart Infusion agar (BHIA; Difco Laboratories), following the same incubation conditions. The bacterial cells were resuspended in saline to reach a final concentration of about $3 \times 10^{8}$ cells $/ \mathrm{mL}$, adjusted to No. 1 MacFarland turbidity standard.

In the experimental model, a split platform was used during the period of inoculation with the biological indicator. The coronal portion of the root canal of each tooth was connected to the cut end of a $1.5 \mathrm{~mL}$ polypropylene Eppendorf tube (Cral, São Paulo, SP, Brazil) using a cyanoacrylate adhesive (Super Bonder, Itapevi, SP, Brazil) and epoxy resin (Durepoxi, São Paulo, SP, Brazil). The tooth-tube connections were entirely coated with two layers of nail polish (Max Factor, Cosmetics and Fragrances, London, UK). The specimens (teeth plus polypropylene tubes) were sterilized in $5 \% \mathrm{NaOCl}$ for $30 \mathrm{~min}$ and rinsed with sterile water for $30 \mathrm{~min}$. The specimens were placed into BHI broth and the test apparatus was incubated at $37^{\circ} \mathrm{C}$ for $24 \mathrm{~h}$ to ensure sterilization. No bacterial growth was observed after this period.

Five milliliters of sterile BHI broth were mixed with $5 \mathrm{~mL}$ of the bacterial inoculum containing E. faecalis and were inoculated using sterilized syringes of sufficient volume to fill the root canal during a 60-day period. This procedure was repeated every $72 \mathrm{~h}$, always using 24-hour pure culture prepared and adjusted to No. 1 MacFarland turbidity standard. The teeth were maintained in a humid environment at $37^{\circ} \mathrm{C}$.

At 60 days, each tooth was removed from its apparatus under aseptic conditions and irrigation was done with $5 \mathrm{~mL}$ of sterile distilled water with sterile syringe. The root canals were dried and refilled with sterile distilled water. Thereafter, sterile paper points (Tanari, Tanariman Ind. Ltda., Manacaru, AM, Brazil; size 45) were introduced into the root canals and maintained for 3 min for sample collection. Each sample was collected using three paper points, which were individually transported and immersed in $7 \mathrm{~mL}$ of Letheen Broth (LB; Difco Laboratories), followed by incubation at $37^{\circ} \mathrm{C}$ for $48 \mathrm{~h}$ in a reduced oxygen atmosphere.

Microbial growth was analyzed by turbidity of the culture medium. Thus, after assessing LB changes, inoculums of 0.1 $\mathrm{mL}$ obtained from the medium was transferred to $7 \mathrm{~mL}$ of BHI, and subsequently incubated at $37^{\circ} \mathrm{C}$ for $48 \mathrm{~h}$. Microbial growth was also checked by turbidity of the culture medium. Gram staining of BHI cultures was used for verification of contamination by E. faecalis. The negative control was used to test sterility and the positive control was used to check bacterial viability throughout the experiment. Therefore, during the 60day period of contamination of the root canals, 2 non-inoculated teeth were kept incubated at $37^{\circ} \mathrm{C}$, as an aseptic control, and 2 teeth were inoculated with E. faecalis, incubated and analyzed under identical conditions.

\section{Preparation for SEM Analysis}

Ten teeth were submitted to metallographic preparation for SEM analysis (JED - JSM -6360LV, Tokyo, Japan), Federal University of Paraná, Curitiba, PR, Brazil at x1,500 and 3,000 magnifications to observe biofilm formation. Root canal length was measured and divided equally into coronal, middle and apical thirds, which were evaluated separately. Two SEM micrographs were obtained from each third, totalizing 60 SEM micrographs. Longitudinal grooves were made along the entire length of each root sectioned and then split with a hammer and chisel.

The images were then analyzed for the presence of $E$. faecalis biofilm on root dentin surface by three previously calibrated observers, using the following scores: 1 . few areas covered by $E$. faecalis biofilm colonizing root dentin surface without invasion of dentinal tubules; 2 . few areas covered by E. faecalis biofilm colonizing root dentin surface with invasion on dentinal tubules; 3 . most areas covered by $E$. faecalis biofilm colonizing root dentin surface and invading dentinal tubules; 4. all areas covered by E. faecalis biofilm, no dentinal tubule 


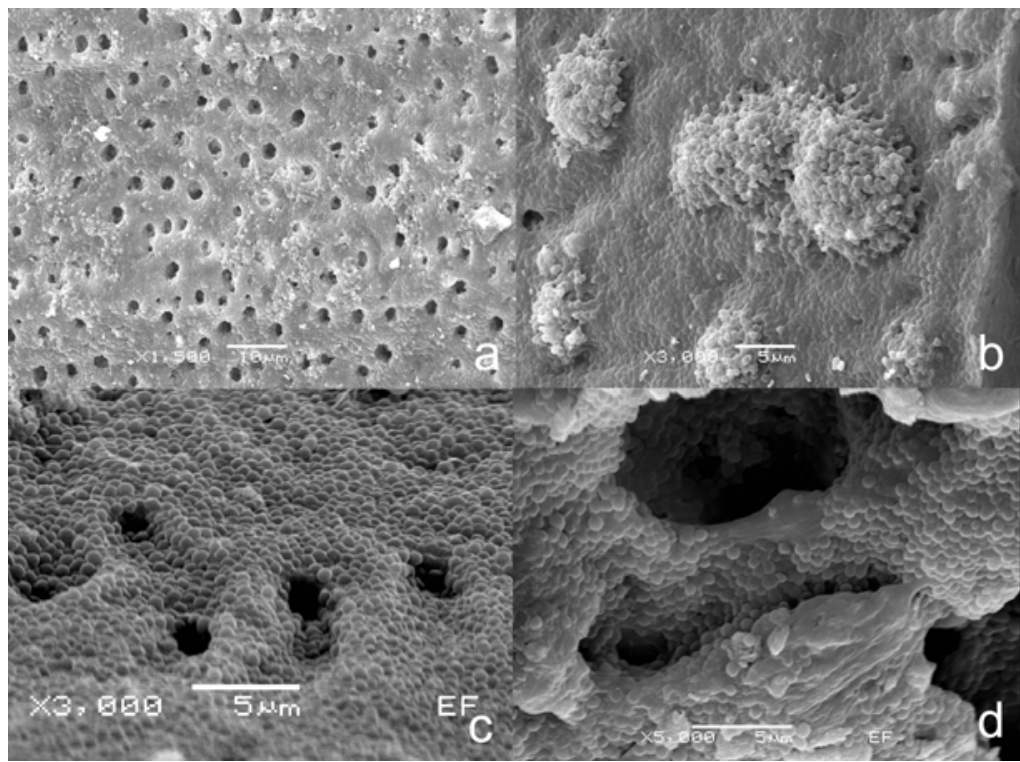

FIGURE 1- Scanning electron microscopy of (a) Various areas covered by E. faecalis biofilm on root dentinal surface (X1,500; Score \#3). (b) Root dentinal surface completely covered by E. faecalis biofilm, and no dentinal tubule openings (X3,000; Score \#4). (c) Evidence of root dentinal surface all covered by E. faecalis biofilm (X3,000; Score \#4). (d) Bacterial penetration in dentinal tubules $(X 5,000)$

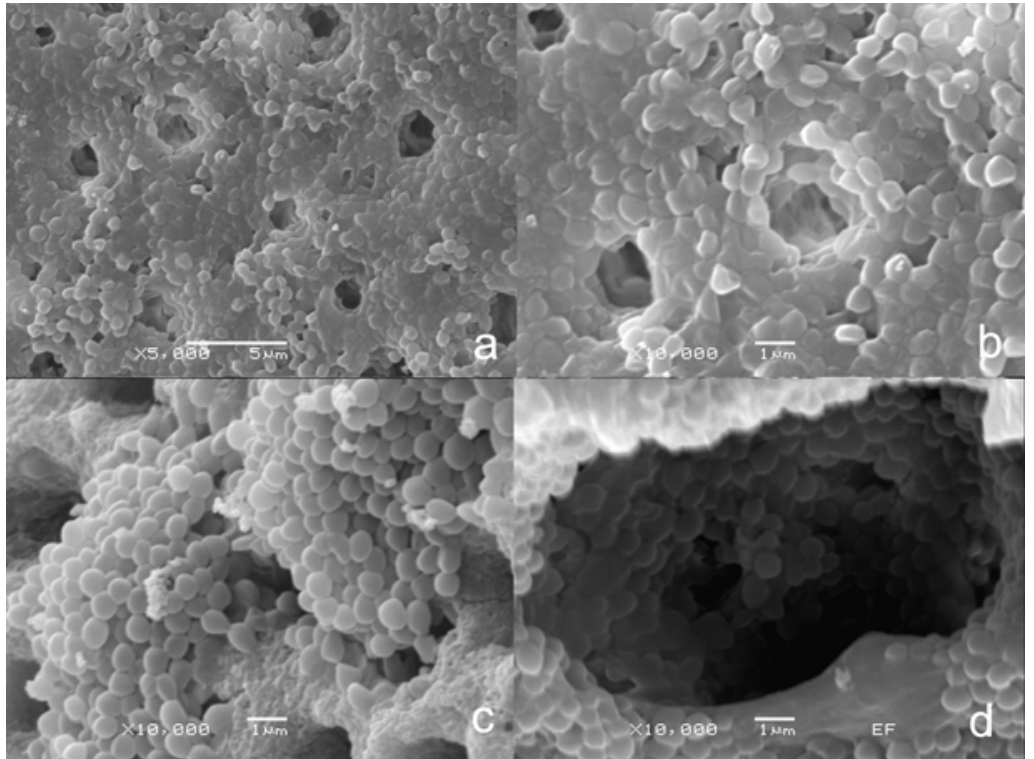

FIGURE 2- Scanning electron microscopy of (a) Root dentinal surface covered by E. faecalis biofilm (X5,000). (b) Magnification area of previous picture (X10,000). (c,d) Aggregated bacterial cells on and in dentinal tubules $(\mathrm{X} 10,000)$

openings.

Statistical analyses of data were performed by KruskalWallis test, to assess significant differences among thirds, and Mann-Whitney U-test, to verify significant differences between the $x 1,500$ and 3,000 magnifications. The level of significance was $5 \%$.

\section{RESULTS}

The analysis of the SEM micrographs showed that the $E$. faecalis biofilm model is a promising model to study the antimicrobial potential of endodontic medicaments. There was no statistically significant difference comparing image magnifications $(p>0.05)$. The coronal and middle thirds showed significantly more areas covered by $E$. faecalis than the apical third $(\mathrm{p}<0.05)$. Figures 1 and 2 show $E$. faecalis biofilm formed on root dentin surface.

\section{DISCUSSION}

Bacteria elaborate a variety of different surface structure appendages that are involved in host colonization. They mediate 
bacterial adhesion to host surfaces, promote invasion of host cells, allow bacterial cell-cell contact and communication, or protect bacteria from host immune defenses ${ }^{15}$.

Numerous biofilm models have been described for the study of intracanal medicaments ${ }^{6,9,22,24}$. The experimental models involve infected human teeth in vivo ${ }^{1,20}$, infected human teeth in ex vivo ${ }^{5,6,24}$, infected dog's teeth in vivo ${ }^{10}$, infected bovine teeth ex vivo ${ }^{9,22}$, biofilm model in membrane filters ${ }^{8,27}$. However, there is limited number of biofilm models with validated studies of antimicrobial strategies. Considering a logical analysis of the facts, three aspects must be considered to discuss a biofilm model to study antimicrobial strategies on endodontic biofilm: the bacterial colonization structure, the biological indicator, and the time necessary for biofilm formation.

The biofilm study model that reflects the real environment is an adequate human root canal with variations and anatomic complexity ${ }^{6,24}$. The invasion of root dentinal tubules by root canal bacteria is a multi-factorial event and a limited number of oral bacterial species have the necessary properties to participate in ${ }^{17}$. The penetration of microorganisms in infected root dentin has shown variations in the experimental model, the biological indicator and the time of incubation employed in the studies ${ }^{7,9,24}$. The development and modification of $E$. faecalis biofilm on root canal and its penetration into the dentinal tubules have been associated with the prevailing environmental conditions ${ }^{7}$. The bacterial colonization structure on dentinal collagen constitutes the natural biological representation. Dentinal tubules contain a considerable amount of unmineralized collagen ${ }^{3}$, and type I collagen serves as an adhesion substrate to oral streptococci ${ }^{16}$. Certainly, bacterial adhesion and plaque formation on artificial surfaces and natural oral hard tissues are different.

The biofilm produced by membrane filter has been employed in some investigations ${ }^{8,27}$. This model may not provide an accurate representation of the antimicrobial efficacy of the tested substance, but has some merits, to which may also be added the lack of need for extracted teeth and timeconsuming preparation ${ }^{27}$.

$E$. faecalis has been used as a biological marker in great part of endodontic studies and its importance for endodontic research is well documented ${ }^{4,7,8,12,14,19,29}$. E. faecalis is a Grampositive coccus, facultative anaerobe, present in human gastrointestinal infections and common in secondary apical periodontitis. Enterococci are variably classified as the second to third most common organisms found in hospital-acquired infections, and $85-95 \%$ of these isolates are $E$. faecalis ${ }^{12,19}$. The virulence of enterococci involves the need of adherence to host tissues, which encounter an environment vastly different during the process of tissue invasion, with higher redox potentials and limited essential nutrients. Infecting enterococci likely express genes favoring growth under these environmental conditions and express factors that permit adherence to host cells and extracellular matrix, facilitate tissue invasion, interfere with immunomodulation, and cause toxin-mediate damage ${ }^{12}$.

The microbial flora of teeth with persistent apical periodontitis presents mainly simple species of Gram-positive organisms. E. faecalis represents the species most commonly recovered, and the overall healing rate of re-treatment was
$74 \%{ }^{29}$. Adhesion to the dentin surface is an essential step that determines the pathogenic potential of $E$. faecalis. The influence of E. faecalis proteases and collagen-binding protein have been studied $^{11-14,21,23}$. Collagen-binding protein, serine protein, Ace and possibly gelatinase are potential virulence factors that give E. faecalis the capacity to bind to dentin ${ }^{11}$. Kristich, et al. ${ }^{14}$ (2004) used independent experimental approaches to characterize biofilm formation by E. faecalis, which forms robust biofilms and its development is modulated by the prevailing environmental conditions. Neither the esp gene product nor the remainder of the genes encoded by the known E. faecalis pathogenicity island is required for the development of biofilms with a complex architecture. A secreted metalloprotease, GelE, enhances biofilm formation of $E$. faecalis but, otherwise, the genetic determinants controlling biofilm development remain unknown. Enterococcal lipoteicoic acid may serve as a virulence factor by modulating inflammatory responses and through facilitation of plasmid transfer ${ }^{12}$. The prevalence, virulence, phenotype and genotype of oral and endodontic enterococci have recently been studied ${ }^{25,26}$. Phenotypic and genotypic evidence of potential virulence factors were identified in endodontic Enterococcus spp., specifically production of gelatinase and response to pherormones.

It has been postulated that $E$. faecalis cells maintain the capability to invade dentinal tubules and adhere to collagen in the presence of human serum ${ }^{17}$. This bacterium persists resistant even in critical environments where nutrients are reduced and in the presence of antimicrobial agents like calcium hydroxide, sodium hypochlorite, chlorhexidine, ozone, etc ${ }^{1,5,6,9,29}$. The use of E. faecalis as a biological indicator in several studies is well documented. Bacterial colonization and invasion of surface and root dentinal tubules add important factors, like nutrient supply and time for colonization.

The ability of E. faecalis to invade dentinal tubule has been reported $^{9,22,24}$. The establishment of the ideal time to contaminate dentin surface and root canal deep layers to form the bacterial biofilm is uncertain. Unquestionably, in an adequate microenvironment, the bacterial biofilm will have a better structural organization within a longer period. In several studies, the time taken for biofilm formation to occur showed varied considerably (15 min to 60 days $)^{5,7,9,22,24,27}$. E. faecalis has shown its important role in endodontic infections, with particular strategies to form biofilm, substantial virulence factors ${ }^{11-}$ $14,19,21,23,25,29$, adherence capacity to dentin collagen ${ }^{11,13,14,17}$, survival in critical environment ${ }^{3}$, and resistance to endodontic therapy ${ }^{15,20,28}$.

Haapasalo and Ørstavik ${ }^{9}$ (1987), employing an in vitro model for dentinal tubule infection using bovine teeth, evaluated antimicrobial effect of camphorated paramonochlorophenol (CMCP) and a calcium hydroxide compound $\left(\right.$ Calasept $\left.^{\mathbb{R}}\right)$ on tubule infection by $E$. faecalis within 28 days. Liquid CMCP proved highly effective inside the tubules, while Calasept ${ }^{\mathbb{R}}$ was quite ineffective. Estrela, et al. ${ }^{5}$ (2007) determined the antimicrobial efficacy of ozonated water, gaseous ozone, sodium hypochlorite and chlorhexidine in endodontic biofilm developed on human teeth within 60 days. The antimicrobial medicaments were not sufficient to inactivate $E$. faecalis. Based 
on this investigations ${ }^{5,9}$ and analyzing various biofilm models ${ }^{5,69,22,27}$, the purpose of this investigation was to review biofilm models and to develop a model system to study antimicrobial strategies.

\section{CONCLUSION}

Problem solving in endodontic biofilm formation involves the establishment of a standard model that compares the antimicrobial efficacy of endodontic materials under several conditions. A model of mature E. faecalis biofilm on human root dentin with 60 days to develop under low oxygen and nutrient-rich environment was suggested in the present study. The proposed biofilm model seems to be viable for studies on antimicrobial strategies, and allows for a satisfactory colonization time of the selected bacterial species with virulence and adherence properties.

\section{REFERENCES}

1- Byström A, Claesson R, Sundqvist G. The antibacterial effect of camphorated paramonochlorophenol, camphorated phenol and calcium hydroxide in the treatment of infected root canals. Endod Dent Traumatol. $1985 ; 1: 170-5$.

2- Costerton JW, Cheng KJ, Geesey GG, Ladd TI, Nickel C, Dasgupta M, et al. Bacterial biofilms in nature and disease. Ann Rev Microbiol. 1987;41:43564.

3- Dai X-F, Ten Cate AR, Limeback H. The extent and distribution of intratubular collagen fibrils in human dentine. Arch Oral Biol. 1991;36:775-

4- Duggan JM, Sedgley CM. Biofilm formation of oral and endodontic Enterococcus faecalis. J Endod. 2007;33:815-8.

5- Estrela C, Estrela CRA, Decurcio DA, Hollanda ACB, Silva JA Antimicrobial efficacy of ozonated water, gaseous ozone, sodium hypochlorite and chlorhexidine in infected human root canals. Int Endod J. 2007;40:8593.

6- Estrela C, Pimenta FC, Ito IY, Bammann LL. Antimicrobial evaluation of calcium hydroxide in infected dentinal tubules. J Endod. 1999;26:416-8.

7- George S, Kishen A, Song KP. The role of environmental changes on monospecies biofilm formation on root canal wall by Enterococcus faecalis. J Endod. 2005;31:867-72.

8- Giardino L, Ambu E, Savoldi E, Rimondini R, Cassanelli C, Debbia EA. Comparative evaluation of antimicrobial efficacy of sodium hypochlorite, MTAD, and Tetraclean against Enterococcus faecalis biofilm. J Endod. 2007;33:852-5

9- Haapasalo M, Ørstavik D. In vitro infection and disinfection of dentinal tubules. J Dent Res. 1987;66:1375-9.

10- Holland R, Otoboni-Filho JA, Souza V, Nery MJ, Bernabe PFE, Dezan E Jr. A comparison of one versus two appointment endodontic therapy in dogs' teeth with apical periodontitis. J Endod. 2003;29:121-5.

11- Hubble TS, Hatton JF, Nallapareddy SR, Murray BE, Gillespie MJ Influence of Enterococcus faecalis proteases and the collagen-binding protein, Ace, on adhesion to dentin. Oral Microbiol Immunol. 2003;18:121-6.

12- Jett BD, Huycke MM, Gilmore MS. Virulence of Enterococci. Clin Microbiol Rev. 1994;7:462-78.
13- Kowalski WJ, Kasper EL, Hatton JF, Murray BE, Nallapareddy SR, Gillespie MJ. Enterococcus faecalis adhesion, ace, mediates attachment to particulate dentin. J Endod. 2006;32:634-7.

14-Kristich CJ, Li Y-H, Cvitkovitch DG, Dunny GM. Esp-independent biofilm formation by Enterococcus faecalis. J Bacteriol. 2004;186:154-63.

15- Lamont RS, Jenkinson HF. Adhesion as an ecological determinant in the oral cavity. In: Kuramitsu HK, Ellen RP. Oral bacterial ecology - the molecular basis. England: Horizon Scientific Press; 2000.

16- Liu T, Gibbons RJ. Binding of streptococci of the mutans group to type 1 collagen associated with apatitic surfaces. Oral Microbiol Immunol. 1990;5:131-6.

17- Love RM. Invasion of dentinal tubules by root canal bacteria. Endod Top. 2004;9:52-65.

18-Marsh PD. Plaque as a biofilm: pharmacological principles of drug delivery and action in the sub- and supragingival environment. Oral Dis. 2003;9:1622 .

19- Murray BE. The life and times of the Enterococcus. Clin Microbiol Rev. 1990;3:46-65.

20- Nair PNR, Henry S, Cano V, Vera J. Microbial status of apical root canal system of human mandibular first molars with primary apical periodontitis after one-visit-endodontic treatment. Oral Surg Oral Med Oral Pathol Oral Radiol Endod. 2005;99:231-52.

21- Nallapareddy SR, Qin X, Weinstock GM, Höök M, Murray BE. Enterococcus faecalis adhesion, ace, mediates attachment to extracellular matrix proteins collagen type IV and laminin as well as collagen type I. Infect Immun. 2000;68:5218-24.

22- Ørstavik D, Haapasalo MPP. Disinfection by endodontic irrigants and dressings of experimentally infected dentinal tubules. Endod Dent Traumatol. $1990 ; 6: 142-9$

23- Rozdzinski E, Marre R, Susa M, Wirth R, Muscholl-Silberhorn A. Aggregation substance-mediated adherence of Enterococcus faecalis to immobilized extracellular matrix proteins. Microb Pathog. 2001;30:211-20.

24- Safavi KE, Spångberg LSW, Langeland K. Root canal dentinal tubule disinfection. J Endod. 1990;16:207-10.

25- Sedgley CM, Lennan L, Clewell DB. Prevalence, phenotype and genotype of oral enterococci. Oral Microbiol Immunol. 2004;19:95-101.

26- Sedgley CM, Molander A, Flannagan SE, Nagel AC, Appelbe OK, Clewell DB, et al. Virulence, phenotype and genotype characteristics of endodontic Enterococcus spp. Oral Microbiol Immunol. 2005;20:10-9.

27- Spratt DA, Pratten J, Wilson M, Gulabivala K. An in vitro of the antimicrobial efficacy of irrigants on biofilms of root canal isolates. Int Endod J. 2001;34:300-7.

28- Sundqvist G, Figdor D, Persson S, Sjögren U. Microbiologic analysis of teeth with failed endodontic treatment and the outcome of conservative retreatment. Oral Surg Oral Med Oral Pathol Oral Radiol Endod. 1998;85:8693.

29- Sundqvist G, Figdor D. Life as an endodontic pathogen. Ecological differences between the untreated and root-filled root canals. Endod Top. 2003;6:3-28.

30- Svensäter G, Bergenholtz G. Biofilms in endodontic infections. Endod Top. 2004;9:27-36. 